\title{
Correction to: Analysis of Water Quantity and Quality Trade-Offs to Inform Selective Harvesting of Inflows in Complex Water Resource Systems
}

\section{Sayani Dey ${ }^{1} \cdot$ Andrew Barton $^{1}$ (D) $\cdot$ Harpreet Kandra $^{1}$ (D) Adil Bagirov $^{1}$ (D) $\cdot$ Kym Wilson $^{2}$}

Published online: 8 December 2021

๑) Springer Nature B.V. 2021

\section{Correction to: Water Resour Manag (2021) 35: 4149} http://doi.org/10.1007/s11269-021-02936-x

The wrong Supplementary file was originally published with this article. The original article has been corrected.

Publisher's Note Springer Nature remains neutral with regard to jurisdictional claims in published maps and institutional affiliations.

The original article can be found online at https://doi.org/10.1007/s11269-021-02936-x.

\section{Sayani Dey}

sayanidey@students.federation.edu.au

1 School of Engineering, IT and Physical Sciences, Federation University, Ballarat, VIC, Australia

2 Grampians Wimmera Mallee Water Corporation, Horsham, VIC, Australia 